Original Article

\title{
How Different Modes of Child Delivery Influence Abdominal Muscle Activities in the Active Straight Leg Raise
}

\author{
Yu-Jeong Kwon, MS, PT ${ }^{1)}$, Eun-Ju Hyung, MS, PT ${ }^{2)}$, Kyung-Hye Yang, MS, PT ${ }^{2)}$, \\ Hyun-OK Lee, PhD, $\left.\mathrm{PT}^{2}\right)^{*}$ \\ 1) Department of Physical Therapy, Dong-Eui Institute of Technology, Republic of Korea \\ 2) Department of Physical Therapy, College of Health Sciences, Catholic University of Pusan: Bugok \\ 3-dong, Geumjung-gu, Busan 609-757, Republic of Korea
}

\begin{abstract}
Purpose] The purpose of this study was to examine the activities of the abdominal muscles of women who had experienced vaginal delivery in comparison with those who had experienced Cesarean childbirth. [Subjects and Methods] A total of 14 subjects ( 7 vaginal delivery, 7 Cesarean section) performed an active straight leg raise to $20 \mathrm{~cm}$ above the ground, and we measured the activities of the internal oblique abdominal muscle, the external oblique abdominal muscle, and the rectus abdominal muscle on both sides using electromyography. The effort required to raise the leg was scored on a Likert scale. Then, the subjects conducted maximum isometric contraction for hip joint flexion with the leg raised at $20 \mathrm{~cm}$, and maximum torque and abdominal muscle activities were measured using electromyography. [Results] During the active straight leg raise, abdominal muscle activities were higher in the Cesarean section subjects. The Likert scale did not show a significant difference. The activities of the abdominal muscles and the maximum torque of the hip joint flexion at maximum isometric contraction were higher in the vaginal delivery subjects. [Conclusion] The abdominal muscles of Cesarean section subjects showed greater recruitment for maintaining pelvic stability during the active straight leg raising, but were relatively weaker when powerful force was required. Therefore, we consider that more abdominal muscle training is necessary for maintaining pelvic stability of Cesarean section subjects.
\end{abstract}

Key words: Modes of delivery, Abdominal muscle, Active straight leg raising

(This article was submitted Jan. 7, 2014, and was accepted Feb. 20, 2014)

\section{INTRODUCTION}

When conducting rehabilitation for women, characteristics specific to the female gender need to be recognized. Low back pain and pelvic pain have a particularly close relationship with pregnancy. A pregnant woman experiences weight gain, anterior movement of the body's center of gravity, increased loosening of ligaments, decreased control and coordination of the neuromuscular system, arm and leg edema, decreases in abdominal muscle function, increased lordosis, and increased mechanical loading of joints etc ${ }^{1-7)}$. These changes are often reversed through natural recover after delivery, but the level of recovery can vary depending on the mode of delivery.

Compared to delivery by Cesarean section, the morbidity rate of mothers after vaginal delivery is less, and their recovery period is shorter. In addition, with vaginal delivery there is a decreased incidence of endometrial infection, and

*Corresponding author. Hyun-Ok Lee (E-mail: holee1225@ naver.com)

(C2014 The Society of Physical Therapy Science. Published by IPEC Inc. This is an open-access article distributed under the terms of the Creative Commons Attribution Non-Commercial No Derivatives (by-ncnd) License $<$ http://creativecommons.org/licenses/by-nc-nd/3.0/> . fewer complications due to anesthesia, or placenta accreta in future pregnancies. However, vaginal delivery can cause weakness of the pelvic floor muscles resulting in problems such as urinary incontinence ${ }^{8,9)}$.

Delivery by Cesarean section generally decreases damages to the pelvic floor muscles (affecting urinary incontinence) but it damages abdominal muscles, and can cause intestinal obstruction, chronic pelvic girdle pain, infertility, or difficulties due to repeated surgery ${ }^{10-13}$. Elisabeth et al. ${ }^{14)}$ conducted a study of female subjects who experienced pelvic girdle pain during pregnancy, investigating the relation between the mode of delivery and pelvic girdle pain which continued after delivery. It was noted that subjects who had Cesarean section were more likely to report that the pain continued after delivery. Almeida ${ }^{15}$ ) also reported a correlation between chronic pain and Cesarean section.

Hilde et al. ${ }^{16)}$ and Hsieh et al. ${ }^{17)}$ conducted studies on the effect of endurance of the pelvic floor muscles on urinary incontinence related to different modes of delivery. Victoria et al. ${ }^{9)}$ reported that urinary incontinence related to impairment of the pelvic floor muscles was more strongly related to vaginal delivery than to Cesarean section. Thus, the literature concerning the mode of delivery is mostly related to the function of the pelvic floor muscles and pelvic girdle pain. Cesarean section causes damage to the abdominal 
muscle resulting from surgery, with the additional possibility of adhesion ${ }^{18)}$. Nevertheless, very few studies related to this issue are to be found. Therefore, the goal of the present study was to investigate the activities of the abdominal muscles during leg raises in relation to the mode of delivery.

\section{SUBJECTS AND METHODS}

The purpose and methods of the study were explained to all the potential subjects of the study, and all voluntarily agreed to participate. This study was approved by the Catholic University of Pusan Institutional Review Board (CUPIRB-2013-039). Fourteen female subjects were selected who were less than 4 months post-delivery (a time when the relaxation of the pelvic girdle due to pregnancy has sufficiently recovered $\left.{ }^{19}\right)$, and without pelvic girdle pain. Seven subjects had experienced vaginal delivery (age: $33.14 \pm 3.67$ years [mean $\pm \mathrm{SD}$ ]; height: $162.14 \pm 4.1 \mathrm{~cm}$; weight: $56 \pm 8.32 \mathrm{~kg}$; BMT: $21.33 \pm 3.28 \mathrm{~kg} / \mathrm{m}^{2}$; time since delivery: $101.57 \pm 5.7$ days; number of children: $1.43 \pm .535)$, and 7 subjects had experienced Cesarean section (age: $33.14 \pm 2.67$ years [mean $\pm \mathrm{SD}$ ]; height: $162 \pm 3.6 \mathrm{~cm}$; weight: $63.57 \pm 9.8 \mathrm{~kg}$; BMT: $24.23 \pm 3.65 \mathrm{~kg} / \mathrm{m}^{2}$; time since delivery: 94.29 \pm 9.79 days; number of children: $1.71 \pm .502$ ).

In this cross-sectional study, all the subjects performed an active straight leg raising (ASLR) in the supine position with straight legs and the feet $20 \mathrm{~cm}$ apart. The instruction to the subjects was "Try to raise your legs, one after the other, $20 \mathrm{~cm}$ above the couch without bending the knees" ${ }^{20)}$. The velocity of raising the leg was not prescribed. Before performing the ASLR, all subjects had their body weight, BMI, and leg length on both sides (from top of trochanter major of the femur to the caudal side of the lateral malleolus of the ankle) measured.

Effort during ASLR was scored by the women on a sixpoint Likert scale: $0=$ not difficult at all, $1=$ minimally difficult, $2=$ somewhat difficult, 3 = fairly difficult, 4 =very difficult, $5=$ unable to perform ${ }^{20)}$.

The maximum torque was calculated as the maximum power, multiplied by the distance from the greater trochanter to above the ankle joint. Three measurements were performed. Each measurement lasted for 5 seconds, and was followed by 30 seconds of rest time.

A surface electromyography (EMG) system (Noraxon TeleMyo DTS Telemetry) was used to record the activity of the abdominal muscles. The recorded EMGs were processed using a personal computer and MyoRearch XP 1.06 Master Edition software. The activities of the internal oblique abdominal muscle (IO), the external oblique abdominal muscle (EO), and the rectus abdominal muscle (RA) on both sides, were recorded by surface electrodes, following the recommendations of SENIAM ${ }^{20)}$ and ISEK ${ }^{21}$, 22) for skin preparation and electrode position. To minimize the impedance of the skin, hair was shaved and the electrode sites were cleaned with alcohol on a cotton swab.

For the measurement of the muscle activities, subjects performed the ASLR in a supine position with straight legs and feet $20 \mathrm{~cm}$ apart for 5 seconds. The first and the last 1 second of each recording were discarded and the middle 3 seconds were converted to root mean square (RMS) values, and normalized to \% MVIC of each muscle, before performing the comparative analysis.

Statistical analyses were performed using SPSS 18 for Windows. The independent t-test was performed to analyze the significance of differences between the groups. The level for statistical significance, $\alpha$, was chosen as 0.05 .

\section{RESULTS}

During ASLR, the Likert scale scores showed no significant difference between modes of delivery, but the maximum torque of flexion of the hip joint was significantly higher in the vaginal delivery subjects $(\mathrm{p}<0.05)$ (Table 1$)$.

During ASLR, activities of the abdominal muscles increased in the Cesarean section subjects and those of the ipsilateral RA and the contralateral EO significantly increased $(\mathrm{p}<0.05)$ (Table 2).

During RSLR, the activities of the abdominal muscles tended to increase in the subjects who had experienced vaginal delivery, but the differences were not statistically significant $(\mathrm{p}>0.05)$ (Table 3$)$.

\section{DISCUSSION}

The abdominal muscles are inserted in the pubic area, and play a significant role in the dynamic stability of the pubic symphysis ${ }^{14)}$. Since Cesarean section incises these muscles, it causes changes to the biomechanical factors affecting the pelvis, and it can result in intra-abdominal adhesions, similar to other types of abdominal surgery ${ }^{23)}$. Changes in muscle tension or the control of movement patterns after Cesarean section has the possibility of affecting the course of recovery. Failure to control movement patterns is related to constant pelvic girdle pain ${ }^{24)}$. The movement control pattern can be affected by many different factors, and it can be changed depending on the load of $\operatorname{tasks}^{25,26)}$. Therefore, in the present study, we investigated the muscle activities related to abdominal muscle change dependent on the mode of delivery during ASLR and RSLR with changing loads.

ASLR is a complex movement, and the primary agonists are the iliopsoas, rectus femoris and adductor longus. For these agonistic muscles to function properly, it is necessary to activate the abdominal muscles to fix the ilium to prevent anterior pelvic tilt ${ }^{27}$. During ASLR, the activity of a healthy subject's abdominal wall occurs on both sides. However, exclusion of the RA, more activity occurs on the ipsilateral side than on contralateral side ${ }^{24,28)}$.

In the comparison of maximum torque of hip joint flexion and effort during ASLR, the Likert scale scores didn't show a significant difference between the two modes of delivery; however, maximum torque was significantly higher in the vaginal delivery subjects. For the hip flexor to exert power against resistance, abdominal muscles need to exert greater power to prevent the anterior tilting of the pelvis. In the Cesarean section subjects, we saw no difference from the vaginal delivery subjects when a low load was applied (as in ASLR), but with a high load, the vaginal delivery subjects were able to exert greater power. During ASLR, the 
Table 1. Effort during ASLR and maximum torque during RSLR

\begin{tabular}{lcc}
\hline & $\begin{array}{c}\text { Vaginal } \\
\text { delivery }(\mathrm{n}=7)\end{array}$ & $\begin{array}{c}\text { Cesarean } \\
\text { section }(\mathrm{n}=7)\end{array}$ \\
\hline Likert scale & $2.29 \pm 1.11$ & $2 \pm 1$ \\
Hip flexion peak torque (kg.m) & $5.95 \pm 5.45$ & $23.43 \pm 6.65^{*}$ \\
\hline Each value represents the mean \pm SE. & \\
*: Statistically significant, $\mathrm{p}<0.05$ &
\end{tabular}

Table 2. Abdominal muscles activation during ASLR (Unit: \% MVIC)

\begin{tabular}{lcc}
\hline & $\begin{array}{c}\text { Vaginal delivery } \\
(\mathrm{n}=7)\end{array}$ & $\begin{array}{c}\text { Cesarean section } \\
(\mathrm{n}=7)\end{array}$ \\
\hline Ipsilateral IO & $22.84 \pm 5.89$ & $28.68 \pm 4.69$ \\
Ipsilateral EO & $9.72 \pm 3.98$ & $12.8 \pm 4.58$ \\
Ipsilateral RA & $4.76 \pm 1.78$ & $7.14 \pm 1.91^{*}$ \\
Contralateral IO & $7.96 \pm 1.98$ & $10.78 \pm 3.36$ \\
Contralateral EO & $9.02 \pm 3.30$ & $14.01 \pm 3.4^{*}$ \\
Contralateral RA & $4.07 \pm 1.62$ & $6.09 \pm 2.69$ \\
\hline
\end{tabular}

IO: internal oblique, EO: external oblique, RA: rectus abdominis Each value represents the mean $\pm \mathrm{SE}$.

*: Statistically significant, $\mathrm{p}<0.05$

Table 3. Abdominal muscles activation during RSLR (Unit: \% MVIC)

\begin{tabular}{lcc}
\hline & $\begin{array}{c}\text { Vaginal delivery } \\
(\mathrm{n}=7)\end{array}$ & $\begin{array}{c}\text { Cesarean section } \\
(\mathrm{n}=7)\end{array}$ \\
\hline Ipsilateral IO & $43.68 \pm 6.11$ & $40.26 \pm 9.71$ \\
Ipsilateral EO & $28.65 \pm 8.22$ & $25.97 \pm 3.95$ \\
Ipsilateral RA & $15.37 \pm 2.81$ & $13.86 \pm 2.49$ \\
Contralateral IO & $27.62 \pm 19.81$ & $19.81 \pm 11.04$ \\
Contralateral EO & $32.91 \pm 13.11$ & $23.85 \pm 5.44$ \\
Contralateral RA & $14.71 \pm 6.93$ & $13.34 \pm 4.74$ \\
\hline
\end{tabular}

IO: internal oblique, EO: external oblique, RA: rectus abdominis Each value represents the mean $\pm \mathrm{SE}$.

Cesarean section subjects showed higher activities of the abdominal muscles than the vaginal delivery subjects.

In both groups, IO on the ipsilateral side showed the most asymmetric activity during ASLR, and in particular, activities of the ipsilateral RA and contralateral EO of the Cesarean section subjects were significantly higher than those of the vaginal delivery subjects. The internal abdominal oblique muscle during ASLR is tonic muscle, and it can be used in a movement strategy to minimize the change of internal abdominal pressure. In low loads such as ASLR, the trunk muscles of one side work dominantly. In the present study, in both groups during ASLR, IO activity during leg raises asymmetrically increased. However, the ratio of the increase was higher in the Cesarean section subjects. The ipsilateral RA and the contralateral EO of the Cesarean section subjects during ASLR were significantly higher than those of the vaginal delivery subjects, meaning that these muscles were utilized more to maintain trunk stability. Beales et al. ${ }^{24)}$ explained that subjects with chronic pelvic pain showed a high-load movement strategy in a comparatively low-load task. A study by de Groot et al. ${ }^{28)}$, which was conducted on women with low back and pelvic pain related to pregnancy, also showed that the muscle activities of subjects with pain increased more than those of healthy subjects during ASLR. Therefore, it can be considered that Cesarean section elicits a movement strategy similar to that utilized by people with pain in the lumbopelvic region. During RSLR, muscle activity was higher than during ASLR in both groups, and especially that of the ipsilateral IO was higher than those of the other muscles. Also, the vaginal delivery subjects showed higher muscle activity than the Cesarean section subjects. This result is in agreement with the results of the study by de Groot et al. ${ }^{27)}$, which found higher activity in subjects without pregnancyrelated low back pain (PLBP) than in subjects with PLBP, when performing RSLR. This means that after Cesarean section, the abdominal muscles can't efficiently exert power when it is needed.

In conclusion, in the present study, we found that the abdominal muscles of women with Cesarean section are utilized more for pelvic stability during ASLR, but can't exert enough power when it is actually needed. Therefore, Cesarean section subjects need more exercises to enhance their abdominal muscles after Cesarean section, since they have less control of their abdominal muscles than vaginal delivery subjects.

\section{REFERENCES}

1) Block RA, Hess LA, Timpano EV, et al.: Physiologic changes in the foot during pregnancy. J Am Podiatr Med Assoc, 1985, 75: 297-299. [Medline] [CrossRef]

2) Brett M, Baxendale S: Motherhood and memory: a review. Psychoneuroendocrinology, 2001, 26: 339-362. [Medline] [CrossRef]

3) Calguneri M, Bird HA, Wright V: Changes in joint laxity occurring during pregnancy. Ann Rheum Dis, 1982, 41: 126-128. [Medline] [CrossRef]

4) Chesley LC: Weight changes and water balance in normal and toxic pregnancy. Am J Obstet Gynecol, 1944, 48: 565-593.

5) de Groot RH, Adam JJ, Hornstra G: Selective attention deficits during human pregnancy. Neurosci Lett, 2003, 340: 21-24. [Medline] [CrossRef]

6) Dumas GA, Reid JG, Wolfe LA, et al.: Exercise, posture, and back pain during pregnancy. Clin Biomech (Bristol, Avon), 1995, 10: 98-103. [Medline] [CrossRef]

7) Dunning K, LeMasters G, Levin L, et al.: Falls in workers during pregnancy: risk factors, job hazards, and high risk occupations. Am J Ind Med, 2003, 44: 664-672. [Medline] [CrossRef]

8) Dietz HP: Pelvic floor trauma following vaginal delivery. Curr Opin Obstet Gynecol, 2006, 18: 528-537. [Medline] [CrossRef]

9) Handa VL, Blomquist JL, Knoepp LR, et al.: Pelvic floor disorders 5-10 years after vaginal or cesarean childbirth. Obstet Gynecol, 2011, 118: 777784. [Medline]

10) Al-Took S, Platt R, Tulandi T: Adhesion-related small-bowel obstruction after gynecologic operations. Am J Obstet Gynecol, 1999, 180: 313-315. [Medline] [CrossRef]

11) Marana R, Rizzi M, Muzii L, et al.: Correlation between the American Fertility Society classifications of adnexal adhesions and distal tubal occlusion, salpingoscopy, and reproductive outcome in tubal surgery. Fertil Steril, 1995, 64: 924-929. [Medline]

12) Miller G, Boman J, Shrier I, et al.: Etiology of small bowel obstruction. Am J Surg, 2000, 180: 33-36. [Medline] [CrossRef]

13) Kligman I, Drachenberg C, Papadimitriou J, et al.: Immunohistochemical demonstration of nerve fibers in pelvic adhesions. Obstet Gynecol, 1993, 82: 566-568. [Medline]

14) Elisabeth K, Bjelland EK, Stuge B, et al.: Mode of delivery and persistence of pelvic girdle syndrome 6 months postpartum. Am J Obstet Gynecol, 2013, 208: 1-7. [Medline]

15) Almeida EC, Nogueira AA, Candido dos Reis FJ, et al.: Cesarean section 
as a cause of chronic pelvic pain. Int J Gynaecol Obstet, 2002, 79: 101-104. [Medline] [CrossRef]

16) Hilde G, Stær-Jensen J, Siafarikas F, et al.: Impact of childbirth and mode of delivery on vaginal resting pressure and on pelvic floor muscle strength and endurance. Am J Obstet Gynecol, 2013, 208: e1-e7. [Medline] [CrossRef]

17) Hsieh $\mathrm{CH}$, Chang WC, Su TH, et al.: Effects of parity and mode of delivery on urinary incontinence among postmenopausal women in Taiwan. Int J Gynaecol Obstet, 2012, 117: 239-242. [Medline] [CrossRef]

18) Weissman C, Eidelman LA, Pizov R, et al.: The Israeli anesthesiology physician workforce. Isr Med Assoc J, 2006, 8: 255-260. [Medline]

19) Abramson D, Roberts SM, Wilson PD: Relaxation of the pelvic joints in pregnancy. Surg Gynecol Obstet, 1934, 58: 595-613.

20) Mens JM, Vleeming A, Snijders CJ, et al.: Reliability and validity of the active straight leg raise test in posterior pelvic pain since pregnancy. Spine, 2001, 26: 1167-1171. [Medline] [CrossRef]

21) Hermens HJ, Freriks B, Merletti R, et al.: SENIAM 8: European recommendations for surface electromyography, deliverable of the SENIAM project. Enschede, Netherlands: Roessingh Research and Development, 1999.

22) Merletti R, Tonio P: Standards for reporting EMG data. J Electromyog
Kinesiol, 1999, 9: 3-5.

23) Morales KJ, Gordon MC, Bates GW Jr: Postcesarean delivery adhesions associated with delayed delivery of infant. Am J Obstet Gynecol, 2007, 196: e1-e6. [Medline] [CrossRef]

24) Beales DJ, O'Sullivan PB, Briffa NK: Motor control patterns during an active straight leg raise in chronic pelvic girdle pain subjects. Spine, 2009, 34: 861-870. [Medline] [CrossRef]

25) Harman EA, Frykman PN, Clagett ER, et al.: Intra-abdominal and intrathoracic pressures during lifting and jumping. Med Sci Sports Exerc, 1988, 20: 195-201. [Medline] [CrossRef]

26) McGill SM, Sharratt MT, Seguin JP: Loads on spinal tissues during simultaneous lifting and ventilatory challenge. Ergonomics, 1995, 38: 17721792. [Medline] [CrossRef]

27) $\mathrm{Hu} \mathrm{H}$, Meijer OG, van Dieën JH, et al.: Muscle activity during the active straight leg raise (ASLR), and the effects of a pelvic belt on the ASLR and on treadmill walking. J Biomech, 2010, 43: 532-539. [Medline] [CrossRef]

28) de Groot M, Pool-Goudzwaard AL, Spoor CW, et al.: The active straight leg raising test (ASLR) in pregnant women: differences in muscle activity and force between patients and healthy subjects. Man Ther, 2008, 13: 68-74. [Medline] [CrossRef] 